\title{
MOBILE LEARNING MODULE SYSTEM WITH LOGO CHARACTERIZATION
}

\author{
Murizah Kassim', Ahmad Eddy Kesuma Suandi, Azlina Idris, Wan Norsyafizan \\ W.Muhamad \\ ${ }^{1}$ Dr. Faculty of Electrical Engineering, Universiti Teknologi MARA, Selangor, Malaysia. \\ murizah@salam.uitm.edu.my
}

\begin{abstract}
This paper presents a development of Mobile Learning Module system that characterized logo and recognized learning module using mobile system. The system is based on computer vision to easy identify logo and information of the course module which is online on server. The developed system is based on image processing, which can control the classification, qualification and segmentation of images hence to recognize the logo Module information. Objectives of the project are first to design Multimedia Learning Module system that uses a mobile phone to interface with online server that compare and classify the captured image and trained into the system's database. Secondly, module is collected and characterization its type of logo on online server and stored notes module that can be accessed globally from time to time. The last objective is to analyze the designed system and techniques of accessing the Modules on more than 36 participants and presents the result. The methodology development of the system consists of three stages which are capturing an image of each course module, recording the logos according to type and related information of identified courses. Mobile hand phone is used and mobile programming is coded on the server. One course is taken as sample for recognized the logo modules. The course module is transferred to pdf and put as accessible mobile online. Course information is characterized and classify by chapter in pdf file through mobile phone. Successfully results presented multimedia modules image logo can be captured and recognition subject name and online module is extracted. Analysis of students used of the system is presented. Students are able to easily access the module anytime, anywhere with recorded accessed. This project is significant to academics which is less complex and relatively faster to capture online module for learning and teaching approach.
\end{abstract}

Keywords: Learning Module, Multimedia, Mobile System, Blended Learning, Online, Logo Characterization. 


\section{INTRODUCTION}

A study explored the effects of using computer-based multimedia learning materials on creative performance using a multimedia learning tool (MLT). The MLT was developed as part of a specific engineering subject which took consideration on the appropriate load on the cognitive system for effective information and creative cognitive processing. Creative thinking results showed that MLT was instrumental for students to generate flexible and original ideas. This was reflected through students' product creativity which showed novel and aesthetic qualities, but lacked practicality. Students' perceptions supported the MLT's partial influence especially through the use of animations ( $\mathrm{H}$. Kassim, Nicholas, \& Ng, 2014). This multimedia learning module characterization with mobile system is built by using software that have image capture to get the data from database. It helps the users to be friendlier and save the time to find what the need using mobile phone. Some trivial multimedia effect presents when items that ask for information contained only in pictures have to be answered, the attention shift to the provided pictures in the learning module can be helpful, as they contain all the information that is needed to answer (Herrlinger, Höffler, Opfermann, \& Leutner, 2017). Others result shows the way of finding the information be easier and can make it faster than system that already implement today. Logo is identified as a key visual element for reader to recognize the starting point or responsibility for archive alongside different elements. The used of programmed recorded picture handling, the principle center of logo discovery is to discover and remove logos with rapid and good quality. Multimedia modules have become ubiquitously available as educational resources in the digital age. Multimedia learning environments has presented that verbal and pictorial representation are to explain and illustrating a subject matter. Multimedia instruction benefits learners that need to construct a coherent mental model from text and pictures by mentally integrating information from both external sources (Scheiter, Schüler, \& Eitel, 2017). A paper reports the findings of a research which looks at the influence of learning styles on engineering students' which presented creative thinking performance when multimedia learning tool is used. The findings indicate that active, reflective, intuitive and high visual students benefit creatively after using the multimedia learning tools (H. Kassim, 2013).

Logo matching and recognition technologies are important for brand advertising and surveillance applications. It discovers either improper or non-authorized use of logos. Logo characterization is an effective logo matching and recognition method to detect logos. The central issues of this technology are fast localization and accurate matching and unveil the malicious use of logos that have small variation with respect to the information data (Tang \& Peng, 2017). The initial step is referred to as logo location, while the second is typically called logo recognition. Machine learning perspective shows logo recognition is viewed as a multi-class order since every logo classification is viewed as a different target class. In this view, the order framework includes two principle stages which are the determination and extraction of educational elements and the development of an arrangement calculation. In such a framework, an attractive list of capabilities can significantly improve the development of a classification algorithm and an effective algorithm can function admirably even with a low specification list of capabilities.

This paper presents a developed Multimedia Learning Module characterization and recognition using mobile system on logo identification that mapped to module chapter for a course. The system based on computer vision to easily identify the information and data regarding the module online. It is based on image processing, which controlled the classification, qualification and segmentation of images and hence to recognize the information. The objectives of the research are first to design Multimedia Learning Module system that uses a mobile system an interfaced with module to compare and classify the captured image with the images that were trained into the system's database. Secondly, data is collected and characterization its type of logo on online server is made. The last objective is to store notes and characterize the module manual and it can be accesses globally from time to time and analyzed on students used of the system is presented. The method development of the system consists of three stages which are capturing an image of the module, recording the logos according to type and related information of identified courses. Hardware such as mobile is used and programming languages based on mobile and server platform being design. It is significant where captured images and multiple recognition clues such as logo and name subject are extracted and characterized which classify and recognize the courses information. The system benefit to academic which this approaches is an easy access and relatively faster system to capture online module for learning and teaching matters.

\section{LITERATURE REVIEW}

Information gathered through internet usages are the new concept of learning known as e-learning or online learning. However, some issues have been determined from online learning such as instance number of student using the system is not encouraging and the impact of the performance of student will affect their knowledge (Akhtar, Warburton, \& Xu, 2017). One known networking academy has developed an innovative 
global education initiative that delivers information and communication technology skills to help meet this growing demand while improving career and educational opportunities for students around the world. A study on globalization students centered has changed the skills and competencies required from engineers hired by industry and service providers in today's world. A research presents the impact of the globalization and industry to the teaching and learning of networking courses at Electrical Engineering Faculty at a University shows the growth and impact of industry-university linkages in Malaysia to higher institutions. The paper presents the industry using an e-learning portal for students test and exams proved the need of e-learning activities to mature students on technology skills (Ab Rahman, Ahmad, Kassim, Ku Haroswati, \& Ku Yahaya, 2009; Rahman, Zan, Abidin, Kassim, \& Yahaya, 2010).

University website called student supporting system or student portal usually exist in most of universities websites. Some of the utilities provided to students are adding and dropping courses, checking exams' results, checking the confirmation slip, reviewing the study plan and many other things (Qawasmeh, Tahir, Tresnjo, Zilic, \& Ibrahim). This research introduced an alternative e-learning that includes interactive multimedia to help undergraduate students learn introductory to programming. The application provides interactivity between students and application so that students can learn independently (Mutiawani, 2014). The intention of the research is to familiarize the idea of multimedia learning into the students' mindset and also to encourage the students to utilize the applications offered by multimedia learning. Student would be required to participate in multimedia learning courses, where their knowledge and skills in multimedia learning could be enhanced. The study in the related topic were conducted along a period of four months by using five parameters and it found that the students' reaction towards multimedia learning is good satisfactory level although majority of the students would still prefer studying using books and notes (Jamaluddin, Hanafiah, Radzi, Zulkifly, \& Noor, 2010).

Comparison study on previous research on captured image presented by some experimental result are studied (Chiu \& Mok, 2017). This experimental study used an instructional visual aid for algebra to investigate whether different order thinking skills that are remembered, understand and analyzed that affected the expertise reversal effect. One hundred and twenty-three secondary school students were assigned to an experimental condition, either with or without the aid. In the experiment, an aid that was designed for novice learners and the materials were developed using multimedia learning principles to maximize the use of learner cognitive capacity. The results showed that the expertise reversal effect occurred in understanding for retention and more-structured but not for more-structured learners. Suggested is identified that designing adaptive environments should take order thinking skill, instructional format and learner expertise into account in the study.

The development of mobile system helps and make easy accessed to students. This help student to identify and rebuilt their skills. Images or logos help students in memorizing notes are one of important objective in developing the mobile system. Some techniques included the size, trajectory, position, and the state of movement of image in the system. Measurable parameters based calculation is proposed in order to distinguish a character from another. Mobile and internet based system presented some proposed of characterization on images accessed. One example is using Quick Response (QR) codes are much of the time utilized the Internet and present $Q R$ interpreting capacity on mobile phones. A standardized identification demonstrates an individual recognizable proof number (ID) by this number in a general sense to accesses some information (Wakahara, Yamamoto, \& Ochi, 2010). The image following in pictures groupings acquired through a camera, situated in a settled position is an issue that could be drawn closer with an exemplary following channel. Instructing and learning material cannot be devised in detachment without connecting up with some instructive goal under an instructive customized command of modified on student's targets level. The increase in the diversity and availability of electronic information led to additional processing requirements, in order to retrieve relevant and useful data where the accessibility problem will occur. This problem is even more relevant for audiovisual information, where huge amounts of data have to be searched, indexed and processed. Most of the solutions for this type of problems point towards a common need which is to extract relevant information features for a given content domain. Thus, mobile technologies are one of the advantages as a communication medium in teaching and learning where easy accessed and faster compared to online client server connections (Wang, Wu, \& Hsu, 2017). No only based on technology or students communications skills, self-learning of students also important to educate them in familiar with the learning environment like internet, online based education (M. Kassim, Kamal, Sani, \& Johari, 2016).

\section{METHODOLOGY}

Method present and explains the design flowchart and the developed of System Block Diagram. 


\subsection{Flow Chart}

A number of classification algorithms were identified on Multimedia learning that are equipped for mobile system. It used images in order to recognize, analyze and process the provided input images based on logo. This project used images processing technology that capture chapter of the learning module and accessed by the students. Figure 1 shows the design method where first parameters of previous system design are analyzed.

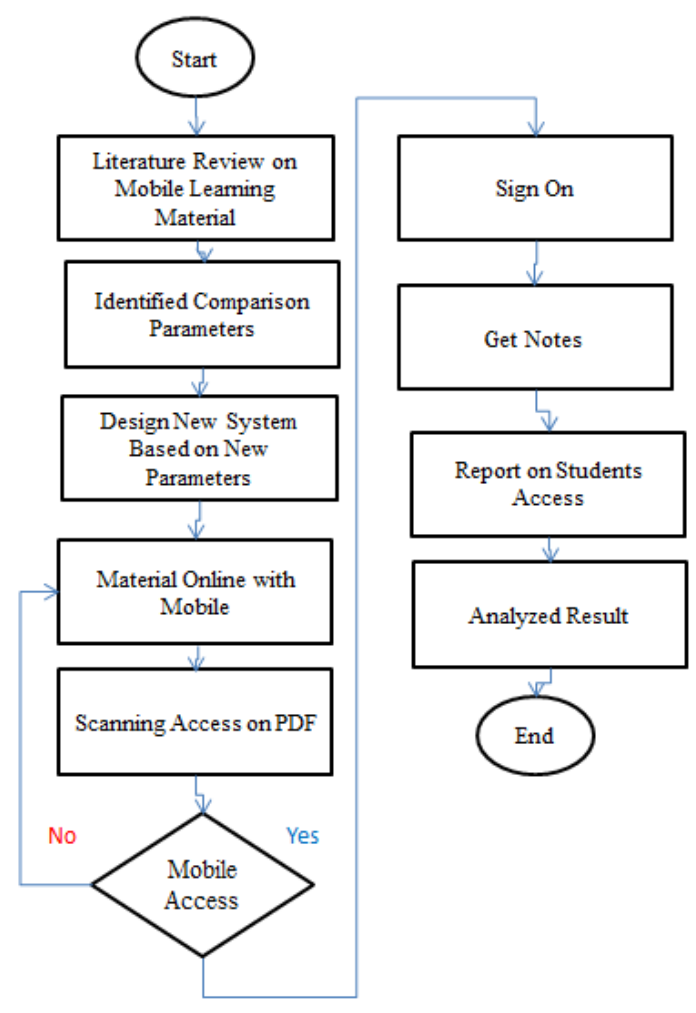

Figure 1 System's Flowchart

\subsection{System Block Diagram}

Figure 2 shows the architecture of the proposed systems. The block diagram presents the mobile learning identification on one course called Multimedia Systems and Applications. It equipped for mobile system that used images in order to recognize each chapter and accessed of students is recorded.



Figure 2 Architectural diagram of the system 
The image captured using the principle of deep learning image processing. The systems classified the logo and images. Learning images of the chapter logo need to be stored first into the database server. After capturing recognition image of logo is done, the capture image logos is processed and analyze by comparing the capture image and learnt image from database server to determine information and data for the image. After comparing process complete, result of the image of the object is send to mobile system. The result shown as adobe pdf file by chapter depended on the image logo captured.

\subsection{Sharp Image Captured}

The developed mobile learning accessed module is significant where control process in the module is designed. The compared images are to determine and classify the input images and logos. Instead of using the standard image processing techniques, Visual Basic Image Processing was used for it provides a much more powerful platform to recognize and classify the logos. Figure 3 demonstrates the execution of Visual Basic when utilizing it for picture plotting. There few reference in strategized or filtered to enhance images to get good picture quality (John \& Nallathambi, 2017). There are two techniques which are color space and feature tracking.

\section{- Colour space}

This is an important part in the system to determine the image which colour it detect to obtain a good result. Using a live camera need to understand the different representation for colour space. There are many colours to browse where each of them has it claim quality and impediments. Moreover, picking the correct colour space for a particular picture also helps to get a decent outcome. The brightness of the image also has a fluency to image detection to make it easier to detect and do a comparison from database.

\section{- Feature tracking}

Feature tracking have guide access to the brightness of the pixel, a basic calculation can be utilized to track an object. The calculation that will be presented here is a genuinely basic one, called the "rectangle calculation". The rectangle calculation monitors four focuses in each edge, the top most, left most, right most and base most focuses where the shine surpasses a specific threshold value.,

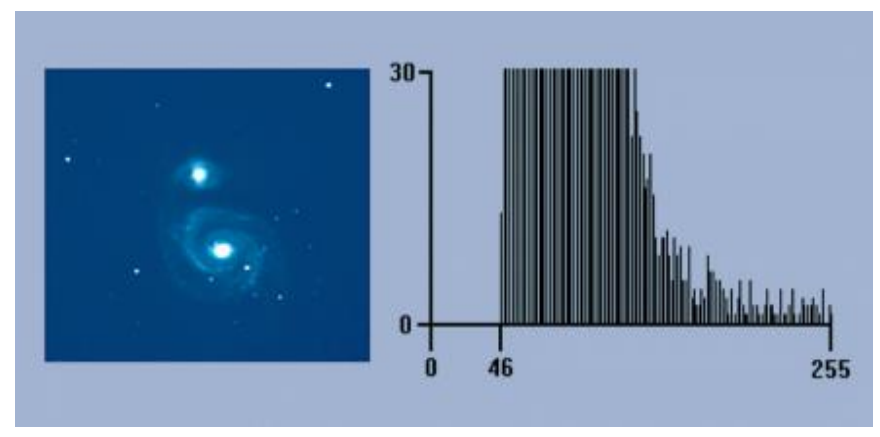

Figure 3. Technique improve disk access and quality image

\subsection{Analysis on Student's Used the System}

Analysis of the developed mobile system is done on 36 participated students. Table 1 presents the questionnaires on used of the system. The survey is based on three important areas that focus to teaching and learning objective in implemented the designed systems which are System Design, Handheld and Access and lastly teaching and learning purposes.

TABLE I. Questionnaires Survey
System Design
1. Does the system design present worthy to be implemented?
2. Does the system easy to handle and accessed by students?
3. Do you like the concept of learning with the design system? 


\begin{tabular}{l} 
Handheld and access \\
1 Does the system support the existing module \\
online? \\
2 Do you think the module on mobile gave the better \\
way on accessing and reading it? \\
3 Do you think module in multimedia helps much in \\
learning process? \\
\hline Teaching and learning purposes \\
1. Does the system benefits to teaching and learning \\
purposes? \\
2. If this system implemented, would it be still classes \\
needed for students? \\
3. Do you think technology will change the present \\
teaching and learning style in the future with the \\
design module? \\
4. Do you think the system which mobility connects \\
with hand phone will change the new learning \\
technology? \\
5. Do you prefer to go to classes or blended learning \\
concept in learning? \\
6. Do you able to commit and do independence study \\
if full blended learning is implemented?
\end{tabular}

\section{ANALYSIS AND RESULT}

Result shows successful of the developed system on classified image of mobile system that accessed the course module.

\subsection{System Design on Mobile.}

Figure 4 shows the example of chapter 1 classify image after the image has been record in the database.

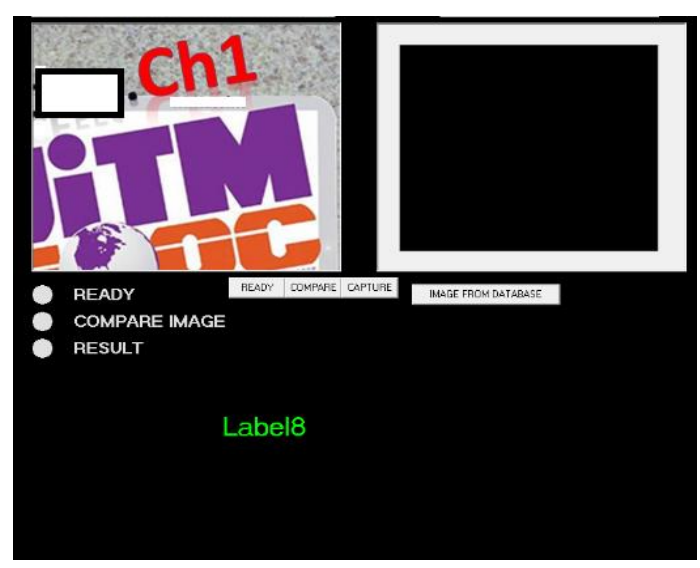

Figure 4 Image to be classified

The design and developed system is successfully done by using an identified mobile system which easily classified the chapter's information from identified captured logo. The system made the finding process to retrieve the information and new updates become less complex and relatively very faster. All module chapters are based on the logo designed according to chapters and name through comparing image and it 
find the best matching image. This system designed platform using mobile to learn the multimedia learning and module characterization.

Figure 5 shows the image comparison from database to get the actual image of the image and the data. It compared from various data that have in the database to get the actual image and bring out the information of the image. After the image has been confirmed, the data will show the image taken. Result from this input image is determined when applying the classification algorithm and comparison from database and the result is analyzed.

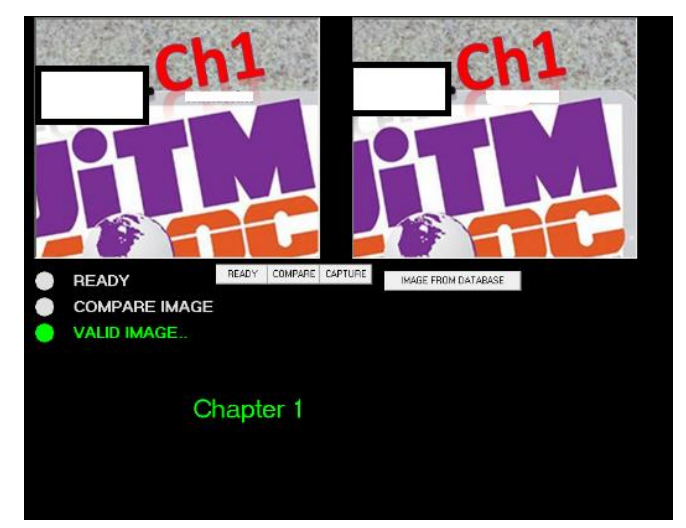

Figure 5 Classified Comparison Image on Database

Figure 6 shows the result that obtains from comparing image in data base. It will obtain a good result when it received $100 \%$ of result in the picture.

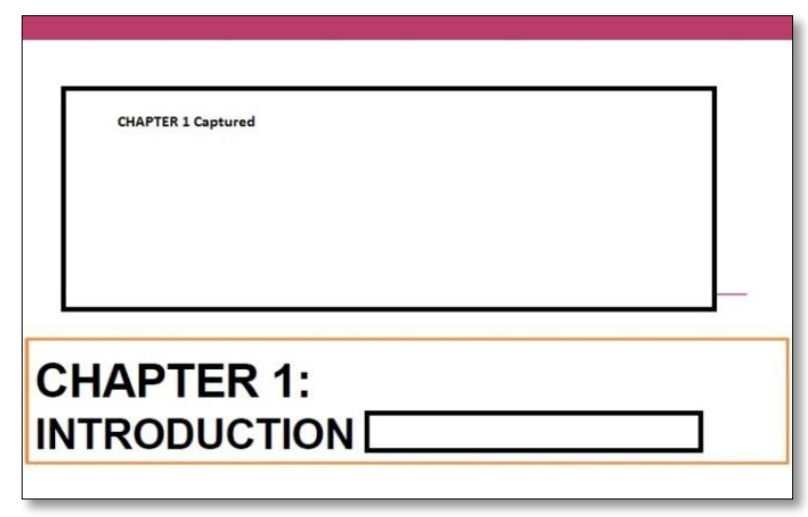

Figure 6 Accesses of chapter 1 Module

Figure 7 shows the process captured if matching do not reached $100 \%$ similarity. Then the accessed based on the chapters logo will pop up a related .pdf file notes based on the logo captured. Both figures show result based on chapter that show after logo has been characterized in database. This result acquired the specific logo of chapters retrieved in getting accessed to the information. 


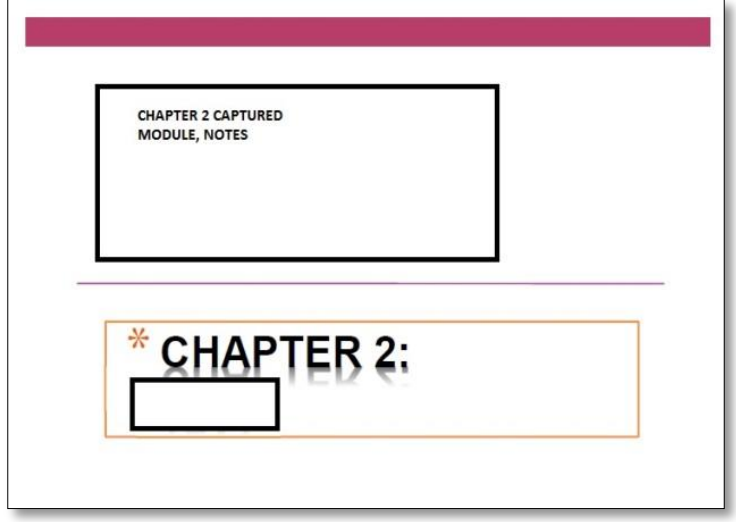

Figure 7 Accesses of Chapter 2 Modules

\subsection{Analysis on Users Used The System}

Table II presents the analysis that has been done on 36 students who used the developed systems. Tested results presents from the 12 questionnaires that have been developed online using Google form after they tested the mobile learning Multimedia system. Likert scale of 5 scales has been sent for all the questions as presented in the table which is Very Good (VG), Good (G), Fair (F), Poor (P) and Very Poor (VP). The analysis presented three main objectives to identified the system design, second is to identified how easy in handling the system that has been developed and third is to identified the teaching and learning concept in using the system.

TABLE II. Data Collections from Derived Questionnaires

\begin{tabular}{|l|r|r|r|r|r|r|r|r|r|r|r|r|}
\hline & Q1 & Q2 & Q3 & Q4 & Q5 & Q6 & Q7 & Q8 & Q9 & Q10 & Q11 & Q12 \\
\hline VG & 10 & 11 & 10 & 9 & 10 & 12 & 8 & 10 & 10 & 12 & 8 & 10 \\
\hline G & 11 & 11 & 11 & 10 & 14 & 12 & 14 & 11 & 13 & 12 & 9 & 5 \\
\hline F & 10 & 9 & 11 & 11 & 6 & 8 & 7 & 7 & 7 & 7 & 14 & 12 \\
\hline P & 1 & 2 & 1 & 2 & 3 & 4 & 1 & 5 & 3 & 3 & 3 & 7 \\
\hline VP & 4 & 3 & 3 & 4 & 3 & 3 & 6 & 3 & 3 & 2 & 2 & 2 \\
\hline
\end{tabular}

\section{- Analysis on System Design}

Figure 8 shows that the graph on survey based on the system design that has been tested by the students. Result shows $87 \%$ agreed based on the result that responded very good, good and fair. Thus the designed system is accepted to be implemented. Result presents that majority of the respondents agreed to the system which presents total of 94 students responded out of total 108 participated. 


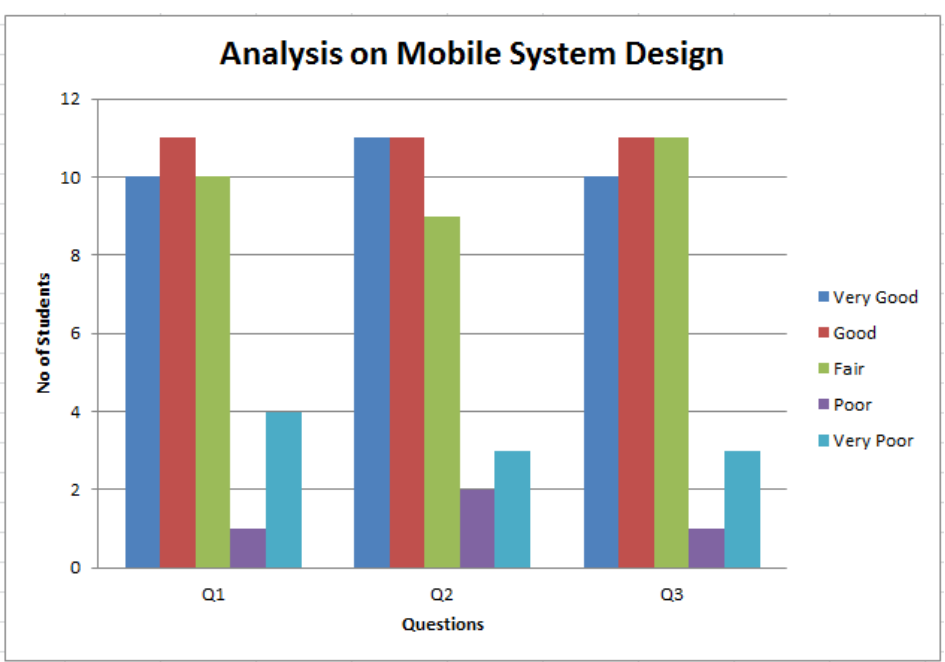

Figure 8 Analysis based on Q1, Q2 and Q3

\section{- Analysis on Handheld and Access System}

Figure 9 shows the graph of respondent on handheld and system accessed of the designed system. Results also presents $85 \%$ agreed to the handheld and access on the design system which support the existing module online. The percentage is on based the responded from survey for very good, good and fair answers on the three questions. Thus the designed system is accepted to be implemented cause of the handheld and easy accessed on the modules online. Result presents that majority of the respondents agreed to the system which presents total of 92 students responded out of total 108 participated on the total of the questions.

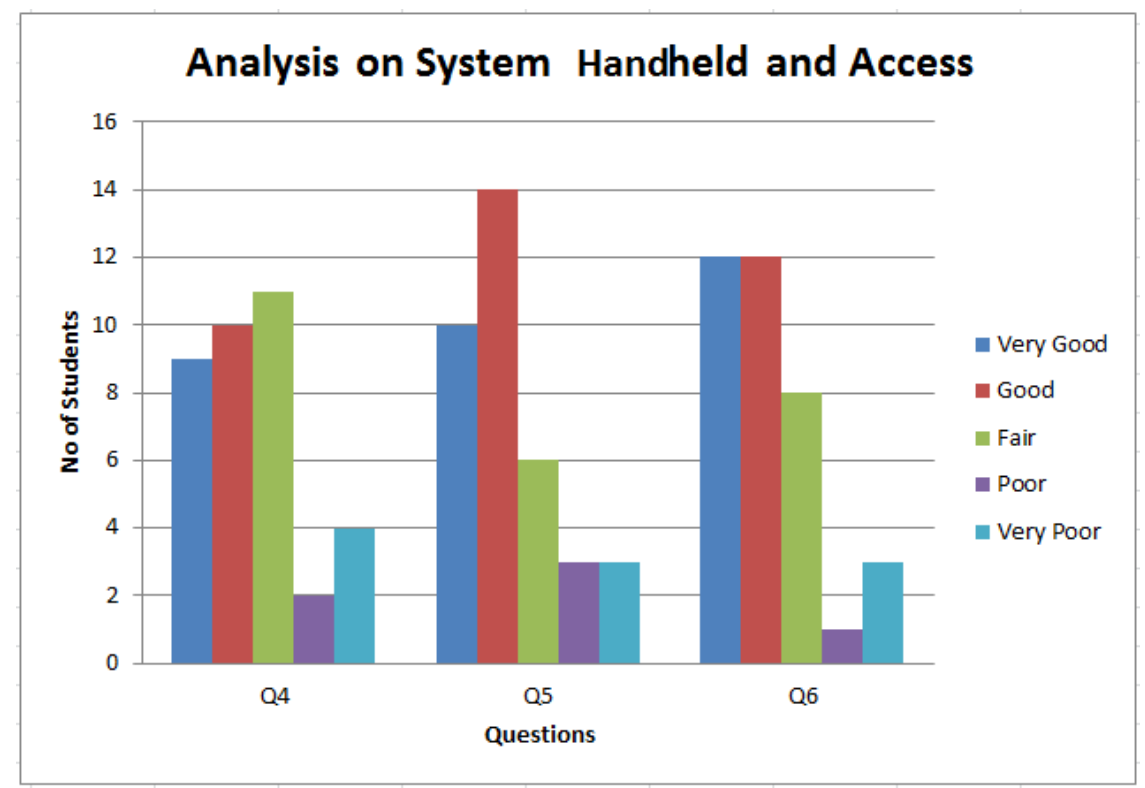

Figure 9 Analysis based on Q4, Q5 and Q6

\section{- Survey of Learning and Teaching Purposes}

Figure 10 shows graph on analysis of benefits to teaching and learning purposes on implementing the designed system. Percentage shows $81 \%$ agreed to the purposed of teaching and learning process on the designed system. Respondent presents 176 agreed out of 216 students on the 6 questions that has tested the system. 


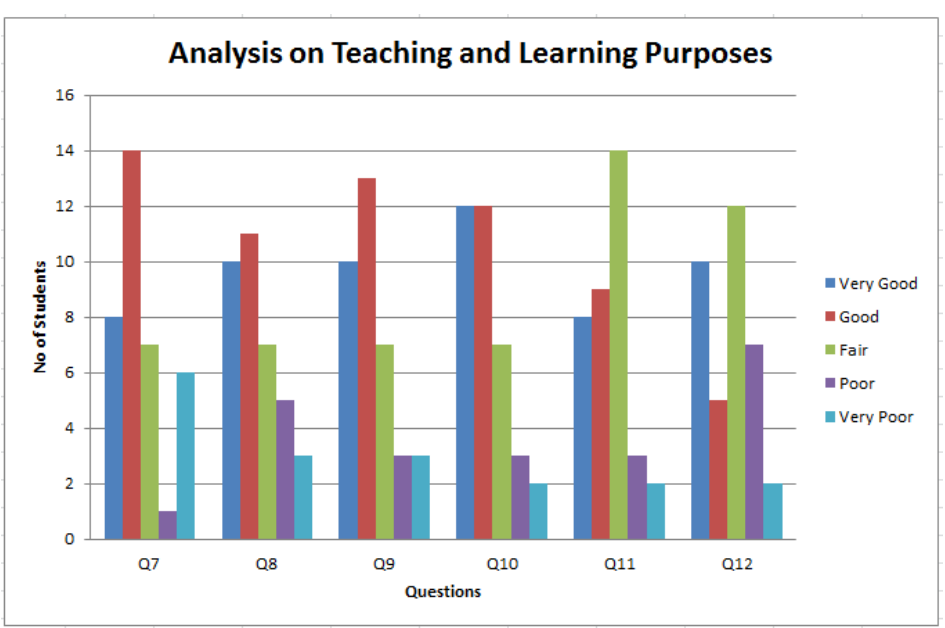

Figure 10 Analysis based on Q7 to Q12

\section{CONCLUSION}

It is testified that mobile accessing system using multimedia with logo and images is an alternative way to manual identification of information. The system is useful to find data and information faster than manually or web based system that take more time. This system has a lot of improvement from the other multimedia learning such as module characterization using phone to determine the information of the subject and the data that needed. Furthermore, it has considered an easier way and faster accessed to gain information. Analysis presents positive input form tested system on students used and survey on system designed, handheld and easy accessed and purpose of teaching and learning systems. Overall more than $80 \%$ agreed on the designed system that to be implemented.

Future considerations are to record the time accessed and quantify number of students or lecturer accessed on the modules analysis and presented the actual used of students data time and accessed reports. This system successfully makes a great impact to education system and can be a new learning module in future.

\section{ACKNOWLEDGMENT}

Authors would like to thank Universiti Teknologi MARA and Ministry of Higher Education (MOHE) for the support grant ARAS number 600-RMI/DANA 5/3/ARAS (27/2015) for this research.

\section{REFERENCE LIST}

Ab Rahman, R., Ahmad, N., Kassim, M., Ku Haroswati, C., \& Ku Yahaya, C. (2009). Case study of a smart collaboration: FEE-UiTM \&amp; Cisco Network Academy experience. [Article]. 2009 International Conference on Engineering Education, ICEED2009 - Embracing New Challenges in Engineering Education, 92-96. doi: 10.1109/iceed.2009.5490605

Akhtar, S., Warburton, S., \& Xu, W. (2017). The use of an online learning and teaching system for monitoring computer aided design student participation and predicting student success. International Journal of Technology and Design Education, 27(2), 251-270.

Chiu, T. K., \& Mok, I. A. (2017). Learner expertise and mathematics different order thinking skills in multimedia learning. Computers \& Education, 107, 147-164.

Herrlinger, S., Höffler, T. N., Opfermann, M., \& Leutner, D. (2017). When Do Pictures Help Learning from Expository Text? Multimedia and Modality Effects in Primary Schools. Research in Science Education, 47(3), 685-704.

Jamaluddin, M., Hanafiah, M., Radzi, S., Zulkifly, M., \& Noor, A. (2010). Promoting E-commerce through Elearning. Paper presented at the Computer Research and Development, 2010 Second International Conference on. 
John, B., \& Nallathambi, S. (2017). Study and Analysis of Filters. Advances in Computational Sciences and Technology, 10(3), 331-341.

Kassim, H. (2013). The relationship between learning styles, creative thinking performance and multimedia learning materials. Procedia-Social and Behavioral Sciences, 97, 229-237.

Kassim, H., Nicholas, H., \& Ng, W. (2014). Using a multimedia learning tool to improve creative performance. Thinking Skills and Creativity, 13, 9-19.

Kassim, M., Kamal, M. M., Sani, M. M., \& Johari, J. (2016). Self-learning website development through online internet knowledge among engineering students. Paper presented at the 2015 IEEE 7th International Conference on Engineering Education, ICEED 2015.

Mutiawani, V. (2014). Developing e-learning application specifically designed for learning introductory programming. Paper presented at the Information Technology Systems and Innovation (ICITSI), 2014 International Conference on.

Qawasmeh, F., Tahir, A., Tresnjo, H., Zilic, A., \& Ibrahim, J. The student portal performance-comparative study (GSM-IIUM).

Rahman, R. A., Zan, M. M. M., Abidin, H. Z., Kassim, M., \& Yahaya, C. K. H. C. K. (2010, 6-9 April 2010). Impact of Globalization and Industry on Engineering Education at Higher Learning Education in Malaysia. Paper presented at the 2010 IEEE Transforming Engineering Education: Creating Interdisciplinary Skills for Complex Global Environments.

Scheiter, K., Schüler, A., \& Eitel, A. (2017). Learning from multimedia: Cognitive processes and instructional support The Psychology of Digital Learning (pp. 1-19): Springer.

Tang, P., \& Peng, Y. (2017). Exploiting distinctive topological constraint of local feature matching for logo image recognition. Neurocomputing, 236, 113-122.

Wakahara, T., Yamamoto, N., \& Ochi, H. (2010). Image processing of dotted picture in the QR code of cellular phone. Paper presented at the P2P, Parallel, Grid, Cloud and Internet Computing (3PGCIC), 2010 International Conference on.

Wang, J.-Y., Wu, H.-K., \& Hsu, Y.-S. (2017). Using mobile applications for learning: Effects of simulation design, visual-motor integration, and spatial ability on high school students' conceptual understanding. Computers in Human Behavior, 66, 103-113. 